\title{
ORALIDADE E ENSINO: UM SABER EM BUSCA DE AFIRMAÇÃO NO COTIDIANO EDUCACIONAL
}

\author{
ORALITY AND TEACHING: KNOWLEDGE IN SEARCH OF AFFIRMATION IN DAILY \\ EDUCATION
}

\section{ORALIDAD Y ENSEÑANZA: UM SABER EN BUSCA DE AFIRMACIÓN EN EL COTIDIANO EDUCACIONAL}

Débora Amorim Gomes da Costa Maciel* Fernanda Queiroz da Silva Abreu**

\begin{abstract}
Resumo: A pesquisa discute as proposições de ensino da oralidade presentes em duas coleções de livros didáticos de língua portuguesa (doravante C1 e C2) destinadas aos anos iniciais de escolarização (1 $1^{\mathrm{a}}$ ao $5^{\circ}$ anos). Visa compreender de que forma o livro didático, enquanto suporte para o ensino-aprendizagem, contribui para o trato do oral, objeto didático em busca de afirmação nas práticas cotidianas dos professores (MARCUSCHI, 2008; MARTINS; 2012). Subsidiamos a discussão teórica à luz da noção de língua como interação (BAKHTIN, 1992) e da noção de oralidade enquanto prática social interativa para fins comunicativos (MARCUSCHI, 2001; SCHNEUWLY e DOLZ, 2004). No trato metodológico, destacamos um conjunto de atividades recorrentes ao longo do projeto didático das obras, cujo objetivo anunciado encaminhava-se para ensinar a oralidade. Estruturamos a análise a partir de uma dimensão qualitativa de pesquisa (MINAYO, 1994) agrupando os dados nas categorias 1) Ensino do Gênero Oral e 2) Ensino da Relação Fala-Escrita. Os resultados demonstram que as coleções favorecem a reflexão sobre a oralidade através de gêneros textuais pertinentes ao trabalho com o referido eixo; contudo, as atividades se concentram em explorar a oralidade no espaço escolar, sem refletir sobre o seu uso em ambiente real de produção. No âmbito da relação fala-escrita, as coleções apresentam perfis diferenciados de compreensão, enquanto a C1 aborda as modalidades na dimensão do contínuo tipológico dos gêneros textuais, a C2 polariza seu olhar e assume uma perspectiva dicotômica. Essa realidade pode ser caracterizada pela incipiência do cenário teórico-metodológico na exploração do referido objeto de ensino.
\end{abstract}

Palavras-chave: Livros didáticos de língua portuguesa. Gêneros textuais orais. Ensino da oralidade. Relação fala-escrita

\begin{abstract}
TThis research discusses the oral teaching proposals present in two collections of Portuguese language textbooks (C1 and C2) for the initial years of schooling (1st to 5th grades). It aims to understand how the textbook, as support for teaching and learning processes, contributes to the oral issues, a didactic object in search of affirmation in the daily practices of teachers (MARCUSCHI, 2008;
\end{abstract}

*Doutora em educação. Universidade de Pernambuco (UPE). deboracostamaciel@gmail.com

** Pedagoga. Universidade de Pernambuco (UPE). fernandaequeiroz@hotmail.com 
MARTINS, 2012). We subsume the theoretical discussion based on the notion of language as interaction (BAKHTIN, 1992) and of the notion of orality as an interactive social practice for communicative purposes (MARCUSCHI, 2001; SCHNEUWLY and DOLZ, 2004). In the methodology, we highlight a set of recurring activities throughout the didactic project of the selected textbooks, considering that the announced goal was to teach orality. We structured the analysis from a qualitative research (MINAYO, 1994), grouping the data into categories 1) Teaching Orality and 2) Teaching Oral-Written relation. The results show that the textbook collection favor the reflection on orality through pertinent textual genres; however, the activities focus on exploring orality only at school, without reflecting on its use in the real conversation practices. In the scope of the Oral-Written relation, the book collection presents different types of comprehension: while $\mathrm{C} 1$ approaches the modalities in the dimension of the typological continuum of textual genres, C2 polarizes its look and admits a dichotomous perspective. This reality can be characterized by the incipience of the theoretical and methodological scenario in the exploration of this subject of teaching.

Keywords: Portuguese language textbooks. Oral textual genres. Orality teaching. Oral-written relations.

Resumen: La pesquisa discute las proposiciones de enseñanza de la oralidad presentes en dos colecciones de libros didácticos de lengua portuguesa (a partir de ahora C1 e C2) destinadas a los años iniciales de escolarización ( $1^{\circ}$ al $5^{\circ}$ años). Visa comprender de qué forma el libro didáctico, en cuanto suporte para la enseñanza-aprendizaje, contribuye para el trato del oral, objeto didáctico en busca de afirmaciones en las prácticas cotidianas de los profesores (MARCUSCHI, 2008; MARTINS; 2012). Subsidiamos la discusión teórica a la luz de la noción de lengua como interacción (BAKHTIN, 1992) y de la noción de oralidad en cuanto práctica social interactiva para fines comunicativos (MARCUSCHI, 2001; SCHNEUWLY e DOLZ, 2004). En el trato metodológico, destacamos un conjunto de actividades recurrentes a lo largo del proyecto didáctico de las obras, cuyo objetivo anunciado se encaminaba para enseñar la oralidad. Estructuramos el análisis a partir de una dimensión cualitativa de pesquisa (MINAYO, 1994) agrupando los datos en las categorías 1) Enseñanza del Género Oral y 2) Enseñanza de la Relación Habla-Escrita. Los resultados demuestran que las colecciones favorecen la reflexión sobre la oralidad a través de géneros textuales pertinentes al trabajo con el referido eje; sin embargo, las actividades se concentran en explorar la oralidad en el espacio escolar, sin reflexionar sobre su uso en ambiente real de producción. En el ámbito de la relación habla-escrita, las colecciones presentan perfiles diferenciados de comprensión, en cuanto la C1 aborda las modalidades en la dimensión del continuo tipológico de los géneros textuales, la C2 polariza su mirar y asume una perspectiva dicotómica. Esa realidad puede ser caracterizada por la insipiencia del escenario teórico-metodológico en la exploración del referido objeto de enseñanza.

Palabras-clave: Libros didácticos de lengua portuguesa. Géneros textuales orales. Enseñanza de la oralidad. Relación habla - escrita.

\section{Introdução}

Em meio às “mudanças paradigmáticas” ocorridas no ensino de língua portuguesa a partir da década de 1990 (RANGEL, 2001, p.10), os gêneros textuais orais e escritos passam a ter maior visibilidade como ferramentas mediadoras do processo de ensino/aprendizagem para todos os eixos de ensino da língua portuguesa (leitura, produção textual, análise 
linguística e oralidade), conforme as orientações apregoadas por todos os documentos oficiais de referência, a exemplo dos Parâmetros Curriculares Nacionais e o Programa Nacional do livro Didático (RANGEL, 2001; COSTAMACIEL, 2013).

Embora exista uma direção explícita nos documentos oficiais (BRASIL, 1996, PNLD, 2010; 2013) de que a oralidade deve ser ensinada, o referido eixo didático continua incipiente nas pesquisas acadêmicas e pouco presente no que diz respeito às investigações do saber docente para o seu ensino, conforme sinalizam as pesquisas desenvolvidas por variados pesquisadores, dentre eles, Mendes (2005), Magalhães (2007), Marcuschi e Dionizio (2005), Marcuschi (2008), Schneuwly e Dolz (2004), Dolz, Schneuwly e Haller (2004), Dolz, Schneuwly, Pietro e Zahnd (2004).

Segundo afirmam Schneuwly e Dolz (2004), o ensino da linguagem oral e o seu uso ocupam um lugar limitado nas escolas em consequência das poucas indicações metodológicas e didáticas e de lacunas apresentadas na formação dos professores. Considerando essas inquietações, nossa pesquisa buscou analisar um dos instrumentos utilizados pelos (as) professores (as) em suas práticas pedagógicas, os livros didáticos. Neles coletamos atividades ligadas à produção e compreensão oral de gêneros textuais, bem como a relação da fala com escrita, em busca de compreender que caminhos apontam tais propostas para o trato com a linguagem oral, no sentido de contribuir para o desenvolvimento da competência comunicativa.

Quais outros elementos dificultam o processo de compreensão oral do oral como objeto didático? Mendes (2005) revela que uma das grandes problemáticas na compreensão sobre o ensino do oral é o fato de a linguagem oral ser considerada, ao mesmo tempo, como prática a ser desenvolvida em produção e compreensão pelos alunos e como ferramenta das intervenções dos professores. A autora apoia-se na discussão trazida pela academia francesa para sinalizar que a dificuldade está na falta de clareza do oral como objeto de ensino, visto que a linguagem oral também é ferramenta de mediação e de comunicação.

Para o processo de didatização do oral, Schneuwly e Dolz (2004) assumem os gêneros orais formais públicos como mediadores do ensino, por compreendê-los como formas de linguagem que apresentam restrições impostas do exterior e implicam um controle mais consciente do próprio comportamento para dominar tais restrições. Em grande parte, são regidos por convenções cujo propósito é regular e definir o seu sentido institucional. Mesmo sendo produzidos, em geral, de forma presencial (face a face), apresentando-se em uma situação mediada, exigem antecipação e necessitam, portanto, de uma ação pedagógica planejada.

É no conjunto das proposições teóricas, sustentáculos das práticas de ensino, que podemos enxergar pressupostos que encaminham o trato da relação do oral sob o ponto de vista da polarização ou dialogicidade. A dicotomização entre as duas modalidades de uso da língua tendem a considerar gêneros diferenciados, apresentados em modalidades distintas, cujas condições de produção, os objetivos, dentre outros elementos, se distinguem.

Dar visibilidade à oralidade não implica ignorar o papel que tem a escola de formar sujeitos competentes no uso da leitura e da escrita (KLEIMAN, 1995; MARCUSCHI, 2001; SOARES, 1999), porém converge para pormos em relevo o lugar e o papel da oralidade nas diferentes práticas de ensino, sejam elas nas propostas dos livros didáticos ou nas ações de ensino dos professores e professoras. 
Dentre os recursos didáticos disponíveis para prática docente, o livro didático se configura, muitas vezes, como único material de acesso ao conhecimento, tanto por parte dos professores que buscam a legitimação de seu trabalho e apoio para suas aulas, quanto por parte dos alunos que se deparam com diferentes estratégias de aprendizagem. A escola, principal responsável pelo ensino, concebe o livro (didático ou não) como um instrumento fundamental, um material essencial na realização das funções pedagógicas exercidas pelo professor (Cf. SILVA, 1996; LAJOLO, 1996; BATISTA, 2001).

Para Silva e Lajolo (1996), Silva e Leal (2011), os livros didáticos ainda são uma referência para a organização e sistematização do ensino nas salas de aulas e, no que se refere ao ensino da língua portuguesa, são suportes que auxiliam no letramento escolar. Este fato aponta para a necessidade de conhecer melhor esse impresso que se converteu na principal referência para a formação docente. Essa realidade motivou a nossa análise a compreender as estratégias didáticas adotadas pelos textos do saber para tratar do oral através dos diferentes gêneros textuais e didatizar a relação do oral com a escrita.

Diante das discussões que movem a investigação, emergem algumas questões de pesquisa, dentre elas: Como a oralidade é tratada pelos livros didáticos? Quais estratégias didáticas são usadas para esse ensino? No que diz respeito à relação fala - escrita, o que é proposto para o ensino? Em qual perspectiva teórica tal objeto de investigação é estruturado? Os manuais de ensino estão colaborando com o fortalecimento da discussão sobre a oralidade e a escrita observando-as em sua proximidade ou em seu distanciamento?

Com vistas a responder algumas questões acima pontuadas, escolhemos duas coleções de livros didáticos, indicadas pelo Programa Nacional do Livro Didático (PNLD), identificadas por nós como C1 e C2, em virtude da necessidade de preservarmos a imagem das obras. Selecionamos exemplos de atividades dispostas no manual do aluno, bem como os comandos de realização dessas atividades indicados no manual do professor (MP), para que pudéssemos ter uma visão geral do propósito didático das obras. As coleções foram identificadas neste estudo por siglas, numerais e letras a eles associados, o que indicará os livros, as coleções, o ano escolar e a página onde aparecem as atividades ou o conteúdo.

Em busca de melhor conhecer o nosso objeto de discussão, imergimos a seguir em uma discussão teórica.

\section{Fundamentação teórica}

É proposta dos documentos oficiais, dentre eles os Parâmetros Curriculares Nacionais (BRASIL, 1997) e do Programa Nacional do Livro Didático (PNLD, 2010), que, no ensino de língua materna, a oralidade seja tratada como objeto de ensino - aprendizagem. Os livros didáticos também recebem orientação do PNLD, no sentido de trazerem em seus conteúdos propostas que abordem a questão da oralidade em suas múltiplas relações com a escrita, sendo orientações um dos critérios de aprovação dos manuais no Guia do Livro Didático/PNLD e na sua efetiva indicação para a aquisição pelas escolas públicas brasileiras.

Mas afinal, o que significa ensinar a oralidade? Ensinar a oralidade é ensinar os gêneros textuais orais, o que implica observar toda a sua condição de produção e realização (CAVALCANTE e MELO, 2006). Esse ensino deve ocorrer através dos gêneros textuais orais específicos, conforme sinalizam os 
documentos oficiais (BRASIL, 1997; PNLD, 2010). Os gêneros textuais, por sua concretude e historicidade, auxiliam os educadores e os educandos no processo de ensino-aprendizagem, constituindo-se para o aluno como um ponto de referência em sua atividade escolar (KOCH, 2002; MARCUSCHI, 2005, 2008).

Os gêneros textuais são "mega-instrumentos" (SCHNEUWLY, 2004) heterogêneos e flexíveis, historicamente construídos em resposta às demandas e atividades socioculturais. A capacidade adaptativa e a ausência de rigidez fazem com que os gêneros textuais sejam um construto histórico que não se centra nem na substância nem na forma do discurso, mas na ação social. Este aspecto ajuda na identificação de muitos gêneros cuja definição é realizada por sua função e intenção (MARCUSCHI, 2002, p 32). Todavia, este fato não implica a eliminação dos elementos que organizam as formas composicionais dos gêneros, visto que estes são estruturados pelo seu "estilo", sua "construção composicional" e seu "conteúdo temático", componentes fundidos no todo do enunciado, indissociáveis, portanto (BAKHTIN, 1997, p.279).

A heterogeneidade e as diversidades das esferas comunicativas conduziram Bakhtin (1997) a distinguir os gêneros em duas categorias: gêneros primários e secundários. Entre os gêneros primários e os gêneros secundários não há uma relação estática, mas um processo inter-relacional, pois, os gêneros primários são assimilados pelos gêneros secundários em seu processo de construção, fazendo com que os gêneros primários adquiram um caráter particular, perdendo a sua relação com o contexto imediato e influenciando os gêneros secundários em seu conteúdo temático, em sua forma composicional e em seu estilo (BAKHTIN, 1997; MENDES DA SILVA e MORI-DE-ANGELIS, 2003; SCHNEUWLY, 2004).
Quando o sujeito age discursivamente em determinada situação, realiza a seleção dos gêneros em função da ação discursiva. A escolha do gênero atende a alguns requisitos essenciais, devendo ser considerados: os objetivos pretendidos, o lugar em que está sendo produzido e quem será o interlocutor (os papéis dos participantes), pois o modelo dos gêneros é adaptado aos valores particulares dos sujeitos, que adotam um estilo próprio ou mesmo favorecem a transformação do modelo (KOCH, 2002).

No processo de ensino-aprendizagem, os gêneros textuais são uma forma concreta que auxilia aos educadores e, por decorrência, aos educandos (KOCH, 2002). O ensino dos gêneros (escritos ou orais) ajudam o aluno a analisar as condições sociais de produção e recepção de textos, oferecendo um quadro de análise dos conteúdos, da organização do conjunto do texto e das sequências que o compõem, das unidades linguísticas e das características específicas da textualidade (DOLZ e SCHNEUWLY, 2004).

As produções de gêneros orais frequentes no cotidiano do aluno já são dominadas por ele, e a escola assume o papel de instrumentá-lo para ultrapassar essas formas orais de produção e confrontar com o oral formal público, produzido de forma mais institucional. Para Dolz e Schneuwly (2004) o oral formal público dificilmente será aprendido se não houver uma intervenção didática. Em outras palavras, os professores, assim como os livros didáticos devem investir nos gêneros formais, tomando-os como objeto de ensino sistemático, a fim de habilitar o estudante a produzir discursivamente de forma eficiente.

Como sugere Marcuschi (1995), enfocar a linguagem oral no ensino de língua não significa ensinar a falar, pois o ensino da fala só será adequado em situações que não são frequentes na vida diária, tais como, por 
exemplo, colocar a voz de forma adequada ao microfone quando se opera num palco de teatro e se tem de dar um recital. Também podem ser ensinadas as técnicas mais adequadas para o desempenho oral em situações formais específicas que não são do saber cotidiano do aluno. Porém Marcuschi (1995) adverte para o fato de que o treinamento do desempenho oral deve ocorrer com naturalidade e, se possível, com um estímulo especial apenas para "finalidades que exorbitem a aprendizagem social natural”.

Ensinar a linguagem oral implica, também, ajudar o aluno a identificar o que se faz quando se fala, apontando aspectos prosódicos e uma série de recursos expressivos como a gestualidade, os movimentos corporais e as mímicas (MARCUSCHI, 2001). É necessário investir na reflexão de que todos os recursos verbais (escritos ou orais) e visuais (estáticos ou dinâmicos) presentes na fala, assim como na escrita, funcionam juntos na construção de sentidos do enunciado. Por isto se diz que "a fala é multimoldal, visto que se realiza através de recursos verbais e visuais” (DIONISIO, 2005, p. 178).

Dar visibilidade à oralidade, entendida como prática social interativa com finalidades comunicativas é evidenciar o lugar e o papel da oralidade nas práticas docentes. Tal oralidade se ancora em pressupostos teóricos que podem caminhar em direção a uma perspectiva dialógica, que percebe a língua em sua modalidade oral ou escrita, implicada em processos interativos e dinâmicos, ou sob o prisma da supremacia das práticas escritas sobre as práticas orais. (KLEIMAN, 1995; MARCUSCHI, 2001; SOARES, 1999).

À medida que a análise da fala (manifestação das práticas orais) e da escrita (manifestação do letramento) é centrada apenas na ótica das diferenças entre as duas modalidades de uso da língua, o confronto dessas modalidades se volta para o "código e permanece na imanência do fato linguístico" (MARCUSCHI, 2001, p.27). Nessa perspectiva, o parâmetro analítico se estrutura na atribuição de um maior grau de complexidade da escrita, e a fala é tomada como o lugar do erro e do caos.

Reconhecemos a existência de diferenças entre a oralidade e a escrita, porém centramos a discussão na relação de aproximação que há entre ambas. Essa posição é norteada pelo contínuo tipológico, cuja orientação assume que a análise entre as duas modalidades de uso da língua deve partir de gêneros textuais próximos em graus de complexidade estilística, bem como em função de suas demandas sociais e propósitos comunicativos (MARCUSCHI e DIONÍSIO, 2005; MARCUSCHI, 2008).

Embasados na perspectiva de língua socio-interativa, devemos considerar que, de fato, há gêneros textuais da oralidade que se assemelham aos gêneros textuais da escrita e tantos outros da escrita que se assemelham aos da oralidade, assim como há determinados gêneros textuais de cada uma das modalidades que se afastam dos seus respectivos protótipos, tendo em comum apenas o fato de ser ou do domínio oral ou do escrito. As comparações dicotômicas da linguagem oral e da linguagem escrita tendem a considerar gêneros diferenciados, apresentados em modalidades distintas, cujos processos de produção, condições de produção e objetivos, entre outros elementos, se distinguem.

Conforme Tannen (1982), as diferenças formais entre os gêneros textuais se dão em função do próprio gênero e do registro linguístico, e não em função da modalidade. Conforme Marcuschi (2001) é o continuum dos gêneros que distingue e correlaciona os textos de cada modalidade de uso da língua, considerando aspectos, tais como, as 
estratégias de formulação, a seleção lexical, o estilo, o grau de formalidade etc. Para Tannen (1983), o envolvimento interpessoal também interfere nas estratégias discursivas, e Bakhtin (1997), aprofundando essa discussão toma a questão das representações sociais como fatores que condicionam o ajustamento na estruturação do texto produzido pelo falante para o seu ouvinte. Assim temos as relações interpessoais e as relações de poder condicionando o grau de (in)formalidade do discurso.

Diante das discussões sobre a fala e a escrita, os princípios gerais do Programa Nacional do Livro Didático, que norteiam a área de Língua Portuguesa para o Ensino Fundamental indicam que um dos objetivos de reflexão sobre a língua é tratar das relações entre a fala e escrita. A proposta concebe a relação entre as modalidades de uso da língua dentro de um quadro de inter-relações, sobreposições, gradações e mesclas, superando o mito de supremacia social e cognitiva da escrita sobre a oralidade.

Fundados nesse encaminhamento, discutiremos o objeto teórico dessa investigação.

\section{Ensino do gênero oral}

A partir da nossa investigação, observamos que as propostas de produção de textos que buscam trabalhar a oralidade se efetivam nas coleções através de variados gêneros textuais, entre eles, aqueles ligados aos espaços públicos de produção, tais como: propaganda, entrevista, exposição oral. Para o desenvolvimento das propostas de atividades, as coleções organizavam momentos de reflexão sobre os gêneros textuais, dando suporte para a construção textual. Vejamos a proposta de C1 no encaminhamento do gênero entrevista (exemplo1) e exposição oral (exemplo 2):

\section{Exemplo 01:}

(C1/L3/U2:68) Os jornalistas fazem constantemente entrevistas coletivas. Vocês sabem o que é isso? É uma entrevista em que vários repórteres [...]. Identifiquem quais são os alunos da turma que têm irmão menor. Qual desses aceita ser entrevistado sobre como é ter um irmão menor? O voluntário deve ir para frente da turma. Os colegas serão os repórteres, fazendo perguntas sobre como é ter irmão menor. Sigam as regras: Quem quiser fazer pergunta, deve pedir a palavra e esperar a sua vez. Escolham perguntas interessantes, que ajude a esclarecer bem o que o entrevistado pensa sobre ter irmão menor [...]. (MP/C1/L3/U2:68) O objetivo da atividade é desenvolver nos alunos as habilidades de formular, de improviso e numa situação de entrevista mais formal que da interação cotidiana que mantém entre si [...]. Por sua vez, os alunos entrevistados terão a oportunidade de desenvolver habilidade de ouvir com atenção às perguntas que lhes são feitas e respondê-las com pertinência, dando um depoimento coerente e bem estruturado [...].

Neste exercício dirigido ao aluno, a preocupação da C1 parece estar ligada a aspectos como: a) definição do gênero textual entrevista; b) ativação dos conhecimentos prévios dos alunos; c) preparação para a realização da atividade; d) consideração sobre os princípios da organização dos turnos conversacionais. Quanto às orientações dadas aos professores, surgem encaminhamentos, tais como: e) consideração sobre a esfera de produção do gênero textual; f) observação para as regras de convívio social. 
Os elementos acima destacados evidenciam o caminho pensado pela atividade no sentido de introduzir o aluno no uso de um gênero textual de domínio público, a “entrevista coletiva”, assim como de orientá-lo quanto a sua produção. A proposta sugere uma atividade de produção textual que leva em conta a necessidade de o aluno se expressar, observando o contexto de produção, a adequação do gênero textual à situação comunicativa e aos objetivos da interlocução.

Como suporte para o desenvolvimento do gênero textual, os conhecimentos prévios são acionados, de modo que as informações trazidas pelo aluno sejam aproveitadas, favorecendo a mobilização dos conhecimentos linguísticos, textuais e de mundo, ativando assim, diferentes estratégias (KLEIMAN, 1995). Considerar os conhecimentos prévios do aluno é um importante princípio para se trabalhar com os diferentes conteúdos de ensino, nas diferentes áreas de conhecimento (BRASIL, 1997, p.50).

Para garantir que o gênero entrevista coletiva seja realizado de forma eficiente, a C1 chama a atenção para dois pontos fundamentais no processo de interação, a observância para os princípios da conversação em que “fala um de cada vez” (MARCUSCI, 1999, p.19) e o desenvolvimento da habilidade da escuta atenta (BRASIL, 1997). Essas são regras do intercâmbio comunicativo que devem ser aprendidas em contextos significativos, tendo função e sentido para o aluno, e não que sejam apenas solicitação e exigência do professor.

Para que o aluno entrevistador se coloque, a atividade sinaliza que ele deverá escolher perguntas representativas, que possam melhor esclarecer o tema em pauta. Dessa forma, há uma preocupação em fazer com que haja interação entre os participantes (entrevistado $\mathrm{x}$ entrevistador), direcionando o evento para uma situação “ideal” de entrevista, de modo que eles "interajam, bem como se modifiquem, se revelem, enfim, cresçam no conhecimento de mundo e deles próprios” (MEDINA, 1986).

No manual do professor há uma ampliação da proposta direcionada ao aluno. Isto ocorre quando a C1 define o tipo de registro que será usado para efetivar a entrevista coletiva, (MP/C1/L3/U2:68): desenvolver nos alunos as habilidades de formular, de improviso e numa situação de entrevista mais formal que da interação cotidiana que mantém entre si, perguntas a um colega em condições de dar um depoimento sobre o tema da discussão. Assim, o uso formal da fala é sugerido, de modo que o aluno venha a usar a fala de maneira diferenciada da que utiliza em seu cotidiano. Do ponto de vista didático, parece haver uma compreensão que o aluno tem domínio das situações cotidianas de produção (guiadas pela informalidade), por isso direcionam o professor a instrumentá-lo de modo que ele possa ultrapassar as formas cotidianas de produção para confrontar-se com situações formais de fala (BRASIL, 1997).

Ainda no MP encontramos indicações para a observância das regras de convívio social, como na sequência (MP/C1/L3/U2:68): os alunos entrevistados terão a oportunidade de desenvolver habilidade de ouvir com atenção às perguntas que lhes são feitas [...] Nesse sentido, a atividade busca desenvolver a habilidade de escuta atenta, visto que o desenvolvimento da oralidade inclui não apenas a capacidade de falar, mas também a capacidade de ouvir e compreender o que foi dito.

$\mathrm{Na} \mathrm{C} 1$ as propostas de atividades com o gênero exposição oral estão atreladas ao tema da unidade, não havendo a eleição, pelo grupo classe, de um subtema a ser desenvolvido. Esta é uma característica das atividades ligadas ao referido gênero, cuja sistemática 
de trabalho perpassa todos os manuais dessa coleção. Vejamos o recorte de uma dessas propostas de exercício, para que possamos compreender como o trabalho se efetiva:

\section{Exemplo 02:}

(C1/L2/U1:16) Cada brincadeira que não é conhecida por todos da turma devem ser descritas pelos alunos que a conhecem: diante da turma descreva o brinquedo - se possível mostrando-o e explicando como funciona. (MP/C1/L2/U1:16) O objetivo do exercício é desenvolver a habilidade de explicar oralmente uma brincadeira apresentando suas regras - produzir um texto oral de instrução e também explicativo. A exposição pode ser assumida por um aluno acompanhado de dois ou três outros que também conheçam a brincadeira, de modo que estes possam ir complementando ou apresentem alguma variação da brincadeira.

A atividade vem proporcionar, na sala de aula, um espaço em que a oralidade possa ser ampliada, partindo de uma proposta contextualizada (BRASIL, 1997), uma vez que a exposição oral é resultado de um trabalho sobre brinquedos e brincadeiras desenvolvido em toda a primeira unidade. Dessa forma, a C2 cria uma estratégia atribuindo sentido à comunicação, já que a culminância, que favorece a produção do gênero oral, é resultado de um trabalho sistemático, estando o aluno envolvido em um contexto de produção favorável ao desenvolvimento da tarefa.

A proposta sugerida no manual do professor evidencia a produção do texto oral, definindo que a exposição terá a prevalência dos tipos textuais instrução e explicação, situados por Schneuwly e Dolz (2004) na ordem do descrever. $\mathrm{O}$ fato de o texto instrucional ser prevalentemente referencial, demanda do seu produtor capacidades de selecionar itens linguísticos adequados à realização do gênero textual, como, por exemplo, verbos no imperativo, índices referenciais (dêiticos), dentre outros, para que dessa forma construa o texto proposto, na medida em que, se orientado pelo professor, reflita sobre o estilo composicional desse gênero textual.

Ao considerarmos a especificidade do gênero instrucional temos que levar em conta a questão da atividade epilinguística realizada pelo aluno no ato da exposição, pois ao produzir o texto instrucional na oralidade o discente poderá sentir necessidade de, por exemplo, reformular a sua fala para ser melhor compreendido, podendo também haver correções no momento da sua fala em função das interferências advindas do seu interlocutor, na medida em que este o interrompa para questioná-lo, corrigi-lo ou complementar o seu raciocínio etc. A atividade epilinguística ocorre não apenas por o aluno saber usar a linguagem, mas por saber também refletir sobre as escolhas linguísticas, atentando, sobretudo para o objetivo do discurso que é passar instruções para o interlocutor (GERALDI, 1997).

Ao sugerir que o trabalho seja organizado em grupo, a C1 oportuniza a troca de experiências além do que contribui para desenvolver nos alunos a adoção de pontos de vista, o que poderá implicar descentrar de si para adotar o pensamento do outro. Vemos também, mesmo que de forma indireta, orientações para a questão do respeito às regras conversacionais, importantes para o desenvolvimento da exposição oral, visto que os ouvintes estarão apoiando o falante, ajudando-o na ampliação da atividade, atentando, porém, para a regra segundo a qual fala um de cada vez.

$\mathrm{Na}$ C2, observamos que o gênero textual propaganda é recorrente nas sugestões 
de atividades. O referido gênero, por vezes, remete à observação de outras propagandas em seu ambiente real de produção, ou seja, o aluno observará diferentes propagandas veiculadas nos meios de comunicação, que serão tomadas como modelo para a construção textual. Vejamos:

\section{Exemplo 03:}

(C2/L1/U6:162) Que tal você se tornar um (a) garoto (a) propaganda? Escolha uma propaganda que esteja passando atualmente na televisão. Com a ajuda de um adulto, procure escrever o texto que é falado para vender o produto. Observe os gestos e o tom de voz usado para chamar a atenção sobre o produto e tente imitá-los. Ensaie bastante, quando você estiver satisfeito com sua atuação, apresente-se para a turma SUCESSO!!!

Nesta atividade, o gênero propaganda efetiva-se enquanto ferramenta para o professor e ponto de referência para os alunos, no sentido de ser uma forma concreta de realização da atividade escolar (KOCH, 2002). A utilização de um gênero textual que faz parte do cotidiano do aluno, embora não seja produzido por ele em situações espontâneas, oportuniza o despertar para os eventos de letramento sociais, que ocorrem fora da prática escolar (MARCUSCHI, 2001).

Como vimos, os eventos de letramento permeiam a atividade, visto que a escrita está presente no desenrolar da tarefa (BORTONIRICARDO, 2004). Nesse contexto, o aluno é posto em situação de produção, mesmo com a ajuda de um adulto. O exercício considerou que o aluno poderia não dominar a escrita por estar na primeira série escolar (nesta fase, dependendo do público, as crianças ainda estão em processo de alfabetização). O adulto, assim, é apresentado na figura de um mediador para a construção da escrita do texto, porém a realização efetiva do gênero textual dá-se na modalidade oral pelo aluno, que terá um texto escrito como base e, após vários ensaios, se apresentará ao público. A preparação para a apresentação é uma das exigências de realização da atividade, sinalizando a importância do planejamento da fala para uma situação de exposição pública, o que implica uma situação monitorada, previamente planejada, exigindo atenção do falante.

O gênero propaganda também foi tomado como veículo para tratar a questão relativa a fenômenos orais, tais como os elementos prosódicos e a gestualidade. Este fato é notado quando a atividade chama a atenção para tais fenômenos (C2/L1/U6:162) observe os gestos e o tom de voz usado para chamar a atenção sobre... Esses recursos são indicados pela coleção, no intuito de fazer com que, na realização do gênero textual, o aluno faça uso desses recursos de forma eficiente. Assim, a multimodalidade se efetiva, visto que será necessária para a efetivação do gênero textual a harmonização dos gestos e tom de voz no intuito de auxiliar na construção de sentido do texto.

A C2 evidencia, com esta atividade, a possibilidade de se trabalhar na perspectiva do letramento, ajudando o aluno a fazer uso de práticas sociais orais e escritas, mesmo que ele ainda não tenha se apropriado do sistema de escrita alfabética. É importante frisar o papel assumido pela mediação do adulto no ato da produção escrita, o fato de a professora ser a escriba da turma no momento da escrita da propaganda está de acordo com uma visão do letramento, tendo em vista que para esta perspectiva o produtor de um texto é aquele que o concebeu pensando-o e levantando 
ideias para construir o seu sentido e não quem simplesmente o grafa ao ouvir outros ditarem sequências de frases e palavras.

Dessa forma, a C2 demonstra compreender que não ser alfabetizado não implica o sujeito ser iletrado, já que, como nos afirmam Morais e Albuquerque (2005), muitos analfabetos fazem uso de técnicas advindas da escrita, enquanto algumas pessoas alfabetizadas fazem pouco uso da escrita, não conseguindo compreender ou mesmo produzir textos cujos contextos de circulação social sejam específicos, por exemplo, preencher formulários ou entender um texto instrucional.

As atividades dedicadas à produção oral dos gêneros textuais são permeadas por situações que simulam um ambiente real de interação. Para a produção oral, a C2 introduz gêneros que exigem do aluno maior preparação para a sua efetivação, visto que, mesmo sendo produzido no espaço escolar, a sua confecção implicava procedimentos não muito comuns em sua vida diária. A atividade que analisaremos a seguir, cujo gênero denominaremos de interação oral de compra e venda, visto que se configura em uma situação de produção textual de compra e venda que não se encaixa em um gênero já antes classificado, reforça o investimento da C2 em contribuir para a construção da competência comunicativa do educando.

\section{Exemplo 04:}

(C2/L4/U4:121) Frente a frente com o “cliente”. Agora, você e seus colegas irão brincar de vendedores. Imagine que você seja um vendedor de livros de histórias, de enciclopédias [...]. Depois de escolher o produto que você irá vender, pense em como convencer as pessoas em adquiri-lo. Crie falas e gestos interessantes para prender a atenção dos "clientes". Em sala de aula, você se apresentará como vendedor e seus colegas serão os “clientes". Se você "incrementar" sua apresentação, escolha uma roupa que você considere adequada à situação.

(MP/C2/L4/U4:52) [...] por fim, propõe-se uma produção de texto oral: os alunos devem no papel de vendedores, convencer os colegas a comprarem determinados produtos. É importante que, em seguida, haja um espaço para comentários sobre a atividade: a performance dos vendedores, os recursos utilizados, a caracterização dos vendedores, as estratégias para convencer os “clientes”.

Neste exemplo, a C2 direciona seus comandos para o aluno, chamando a atenção para os seguintes pontos: a) preparação para a produção; b) utilização de estratégias argumentativas; c) consideração sobre o interlocutor; d) simulação de ambiente real de produção; e) observação para os aspectos multimodais do gênero textual; f) criação do momento de avaliação da atividade. Aspecto este observado no MP.
A atividade inicia sua proposta sinalizando para o aluno o cuidado com o planejamento da tarefa. A organização prévia oportuniza a observação de elementos essenciais para a realização do gênero, visto que o gênero textual em questão exige um texto adequado para a venda, de forma que os argumentos do "vendedor" convençam o "cliente" a comprar o que se está oferecendo.

Na perspectiva de Rubio e Arias (2002), a argumentação é configurada quando 
"um sujeito tenta persuadir um destinatário acerca de um ponto de vista determinado”. Para as autoras, o ensino da argumentação implica colocar em prática uma diversidade de estratégias com a finalidade de chegar ao objetivo pretendido. A partir desse ponto, os autores defendem tarefas que partam de situações reais em que os alunos possam compreender argumentos dos discursos sociais nas duas modalidades de uso da língua, assim como colocar em práticas diferentes estratégias argumentativas.

Na atividade acima, a produção enquadrada na ordem do argumentar não surge de uma situação verdadeira, como propõe os autores supracitados, visto que o ambiente escolar não se configura como um espaço de “situação de venda". No entanto, parece que, em busca de aproximar a atividade de uma situação real de produção, a C2 organiza o evento (venda) utilizando-se de produtos que, em sua maioria, fazem parte do cotidiano escolar dos alunos. A tarefa (re)cria uma situação que busca reproduzir as práticas de linguagem de referência. (SCHNEUWLY e DOLZ, 2004).

Podemos analisar a atividade da C2 na perspectiva de Schneuwly e Dolz (2004) para quem a introdução de um gênero textual na escola é ressignificada, pois passa a ser gênero a aprender, embora permaneça gênero a comunicar. Como resultado de uma decisão didática, a escolha de determinados gêneros visa a objetivos de aprendizagens que caminham em dois sentidos: melhor conhecê-lo ou apreciá-lo, para melhor saber compreendê-lo, para melhor produzi-lo na escola ou fora dela; e para desenvolver capacidades que ultrapassem o gênero e sejam transferíveis para outros gêneros próximos ou distantes. Nesse processo ocorre a variação do gênero de origem ocasionando transformações, de variada intensidade, tais como simplificação do gênero textual, ênfase em certas dimensões etc.
A proposta da C2 demonstra que o seu objetivo central não é, essencialmente, fazer com que o aluno aprenda a vender, embora pareça "visar o domínio, o mais perfeito possível do gênero textual correspondente à prática de linguagem, para que o aluno possa responder às exigências comunicativas com as quais ele se confronta" (SCHNEUWLY e DOLZ, 2004, p. 79). Os encaminhamentos ofertados para a realização da atividade sugerem o desenvolvimento de habilidades que excedem ao gênero trabalhado, enfatizando dimensões que dialogam com uma infinidade de gêneros textuais, tais como: carta ao leitor, resenha crítica, debate, carta de reclamação, artigos de opinião, ensaios, requerimentos, cartas de solicitação, etc. em que predominam a sequência argumentativa (DOLZ e SCHNEUWLY, 1996), ou mesmo outros gêneros textuais dispostos em diferentes domínios. É nesse sentido que parece caminhar esta atividade.

Como é perceptível, as orientações dadas ao aluno e ao professor sinalizam um repertório de objetivos, direcionados ao ensino de diferentes elementos, entre eles, os aspectos multimodais presentes nos gêneros textuais. Segundo Dionísio (2005), a multimodalidade discursiva é um traço característico dos gêneros textuais orais e escritos, visto que, ao empregarmos a língua nessas modalidades, utilizamo-nos de, no mínimo, dois modos de representação, dentre os quais a autora cita: palavras e gestos, palavras e entonação, palavras e imagens, palavras e tipografia, palavras e sorrisos, palavras e animações, etc. Esses são recursos multimodais.

A observância para a multimodalidade discursiva do gênero textual pode ser conferida quando a $\mathrm{C} 2$ orienta ao aluno no sentido de que (C2/L4/U4:121): Crie falas e gestos interessantes para prender a atenção dos “clientes”. Em sala de aula, você se apresentará como vendedor e seus colegas serão os “clientes". Se você "incrementar" sua 
apresentação, escolha uma roupa que você considere adequada à situação. A partir de uma situação de venda, o aluno terá a função de convencer o cliente a comprar um determinado produto: para isso, ele deverá além de argumentar com precisão, harmonizar as palavras com os gestos, com roupas adequadas ao contexto de produção.

Assim, percebemos que a utilização do gênero textual interação oral de compra e venda vem conjugada com recursos verbais e visuais, atuando como um todo no processamento do gênero textual. Esses recursos são importantes, uma vez que se há de fato a preocupação em desenvolver competências sociodiscursivas nos discentes, precisa-se atentar para o fato de que parte do significado do discurso interacional é construída com base em elementos paralinguísticos como gesto, entonação, olhar, dentre outros, e não apenas com base na estrutura linguística dos enunciados (GUMPERZ, 1982; MARCUSCHI, 2002, 2005). Nessa perspectiva, a multimodalidade presente na atividade analisada contribui para o processo de argumentação, tendo em vista que acompanha a estratégia de convencimento dos ouvintes.
No MP observamos um comando específico para a produção de um texto oral e, mesmo não havendo uma orientação clara para o gênero textual que deverá ser produzido, a C2 dá ênfase à elaboração de um gênero argumentativo (DOLZ e SCHNEUWLY, 2004, p. 58). A situação de aprendizagem se amplia na medida em que o trabalho leva a um momento de reflexão coletiva sobre as formas empregadas nas falas dos alunos “vendedores”.

\section{Ensino da relação fala - escrita}

As atividades aqui analisadas foram destacadas, em meio às propostas das coleções, para que pudéssemos discutir os encaminhamentos ofertados para o trabalho com a relação fala - escrita. Dessa forma, refletimos sobre as estratégias didáticas dispostas nas coleções, no sentido de favorecer a compreensão do aprendiz sobre os usos da língua.

Vemos que dentre as atividades apresentadas pela C2, o gênero textual entrevista foi usado como ferramenta didática no sentido de ensinar a relação da dimensão em foco em nossa pesquisa. Observemos.

\section{Exemplo 05:}

(C2/L1/U3:72) Leia o texto a seguir

fragmento 1 - "Meu nome é Celina Tembé porque sou da tribo Tembé. Estou começando a aprender a língua de nossa tribo. Gosto de viver perto do rio, quero ficar aqui o resto da vida” [...]

Discuta com sua professora e colegas

(C2/L1/U3:77) Como você pode observar, o texto de Celina está entre aspas (“ ”). Isso deveria significar que a pessoa que o escreveu reproduziu integralmente, fielmente, as palavras de Celina. No entanto, percebe-se que isso não ocorreu, pois o texto não apresenta as marcas próprias da fala, mas sim as marcas próprias da escrita. A seguir, leia como, possivelmente, Celina teria falado sobre ela. 
(C2/L1/U3:78) fragmento 2 Eu me chamo Celina, Celina Tembé. Eu sou da tribo Tembé. Eu tô começando a aprender a língua da tribo Tembé. Eu gosto de viver perto do rio. Eu quero ficar aqui o resto da vida. Eu adoro a floresta. Eu fico triste quando as pessoas derrubam as árvores das florestas [...]

Observem que, na linguagem falada, geralmente costumamos:

- Usar frases curtas para expor as idéias, uma a uma, sem estabelecer muita relação entre elas;

- Repetir palavras, expressões e até mesmo frases;

- Usar uma linguagem mais simples, menos elaborada;

- Reduzir alguns sons das palavras.

(MP/C2/L1/U3:47) A questão (...) chama a atenção para a relação linguagem escrita linguagem oral. Para isso, reproduz-se o possível depoimento oral de Celina, com as características próprias da fala. Nessas atividades, espera-se que os alunos desenvolvam competências que permitam:

a) distinguir aquilo que é específico da linguagem escrita;

b) perceber diferenças entre a linguagem escrita e oral;

c) analisar e refletir sobre recursos linguísticos próprios da escrita.

A atividade acima traz o recorte da entrevista dada por Celina, uma criança indígena pertencente à tribo Tembé, a uma revista direcionada ao público infantil. Ao tratar o primeiro fragmento, a questão indica ao aluno que o texto apresentado na revista não condiz com o texto falado espontaneamente pela entrevistada, visto que, por aquele estar entre aspas, deveria apresentar as marcas próprias da oralidade e não as da escrita. Inicialmente a C2 não deixa evidente o que está chamando de “marcas próprias da escrita”, embora dê a entender que esteja tomando a ausência de repetições e os elementos que dão encadeamento ao texto como marcas da escrita. As inferências apontam para esse entendimento, já que a C2, ao tentar produzir a fala no fragmento dois, retira os elementos conectivos e insere repetições forçosas para sinalizar a presença de marcas, que diz ser "próprias da oralidade".

Ao confeccionar uma fala que não tenha sofrido qualquer tipo de edição na passagem para a versão escrita, a C2 artificializa o discurso deixando-o com uma estrutura de texto cartilhado, fragmentado, apresentando de modo forçado a repetição do pronome Eu e a contração do verbo estar = Tô, na tentativa de tornar essa versão próxima da "fala real”. Nesse sentido, a atividade evidencia a língua falada enquanto possuidora de uma estrutura simples ou mesmo desestruturada, informal, concreta e dependente do contexto, enquanto a escrita é apresentada como tendo uma estrutura complexa, formal e abstrata, estabelecendo assim polarizações entre fala e escrita (FÁVERO, 2000).

Com essa posição, a C2 evidencia uma concepção estruturalista, na qual a linguagem é compreendida como expressão do pensamento, submissa a regras pré-estabelecidas pela gramática normativa, esta que prescreve a fala e a escrita corretas. Há também indícios de uma visão transformacionalista, visto que a atividade demonstra compreender a linguagem como um código a ser dominado pelos falantes a fim de que a comunicação seja realizada (TRAVAGLIA, 1995). Ao sinalizar tais posições, a C2 se contrapõe a concepção de língua enunciativa, em que o discurso é 
assumido como prática social e uma forma de interação. Nessa visão, inúmeros elementos são considerados ao se observar a língua, dentre eles a relação interpessoal, o contexto de produção dos textos, as variadas situações comunicativas, os gêneros textuais que servem de veículo para a produção e realização do discurso, a interpretação e a intenção de quem os produz. Sob essa ótica, expressão deixa de ser analisada como uma representação da realidade, mas o resultado das intenções de quem a produziu e o impacto que terá no interlocutor.

A atividade também parece não atentar para o fato de que o primeiro fragmento possa ser a fala literal do sujeito entrevistado, já que este poderia ter se preparado para a entrevista e a sua fala estar mais próxima daquela apregoada pela gramática normativa, ou mesmo de um texto escrito guiado por essa norma. Como afirmam Dolz e Schneuwly (2004), um texto falado pode apresentar uma grande proximidade com o texto escrito como, por exemplo, uma conversa informal e um bilhete familiar que, embora sejam produzidos em modalidades distintas, possuem semelhanças. A entrevista escrita, por exemplo, pode ou não conter marcas da oralidade, da mesma forma que uma entrevista falada ao vivo pode se aproximar de um discurso formal, seja oral ou escrito. Essa perspectiva de análise desestabiliza o conceito trazido pela C2 nesta atividade e dimensiona a análise da relação fala - escrita para suas múltiplas relações.

Conforme Marcuschi (2001), a oralidade e a escrita possuem características próprias; assim, a escrita não consegue reproduzir fenômenos orais tais como os gestos, as prosódias, os movimentos corporais e faciais, por outro lado, a fala não consegue representar elementos significativos da escrita como, por exemplo, o tamanho das letras, cores e formatos. Entretanto, a escrita resgata elementos da oralidade através de marcas gráficas, por exemplo, o ponto de exclamação, o ponto de interrogação etc. Fato este que a atividade parece ignorar.

No MP encontramos afirmações de que a questão foi direcionada para que o aluno percebesse (MP/C2/L1/U3:47) “a relação linguagem escrita linguagem oral. Com esse propósito, aponta algumas habilidades a serem apropriadas” (MP/C2/L1/U3:47): “a) distinguir aquilo que é específico da linguagem escrita; b) perceber diferenças entre a linguagem escrita e oral. No entanto, como podemos notar, tais habilidades incidem na reflexão sobre as diferenças entre a fala e a escrita e não nas relações entre elas, como propõe o comando”. Sendo assim, a atividade apresenta lacunas no sentido de estabelecer uma prática significativa, dificultando o processo de reflexão por parte dos alunos e aumentando a responsabilidade do professor no sentido de intervir com clareza no aprofundamento da questão.

Passemos agora a observar uma das atividades trazidas pela C1 em busca de refletir sobre a relação fala - escrita. Para tal proposta, a referida coleção trabalha o gênero textual carta e endereça encaminhamentos diferenciados daqueles observados na atividade proposta pela C2, acima analisada. Observemos a condução da atividade: 


\section{Exemplo 06:}

$$
\text { (CC1/L4/U2:81,82) (Fragmento 1) Ângela, }
$$

Depois que você foi embora para Ribeirão Preto, eu fiquei um tempão andando pela casa que nem barata tonta, achando tudo muito engraçado...

Observe que Marisa escreve como se estivesse conversando com Ângela. Se ela estivesse falando com Ângela, e não escrevendo para Ângela, com certeza falaria assim mesmo como escreveu? Imaginem se a frase tivesse começado assim:

\section{(Fragmento 2) Ângela,}

Depois que você partiu tudo aqui se tornou muito tedioso. Sinto-me muito entediada por ter de esperar as próximas férias para que possamos nos encontrar de novo...

Vocês acham que Marisa conversaria assim com Ângela? Por que sim ou por que não?

(MP/ C1/L4/U2:81,82) O objetivo das atividades é que, pela observação do texto e de outros exemplos, os alunos intuam que língua oral e língua escrita não se diferenciam de forma absoluta: o uso, na carta, de registro coloquial ou formal depende do destinatário e do objetivo da carta. 1- Ler e discutir com os alunos as modificações feitas na linguagem da carta.

O exemplo 2 simula uma situação de interação face a face, em que o envolvimento entre os interlocutores propicia um registro guiado pela informalidade ( $1^{\mathrm{a}}$ versão da carta) e outro guiado pela formalidade ( $2^{\mathrm{a}}$ versão da carta). Vemos que, na segunda versão da carta, há um apagamento das expressões “tempão andando” e "barata tonta” cuja função seria promover maior proximidade interacional, sendo o texto reformulado para "Depois que você partiu tudo aqui se tornou muito tedioso. Sinto-me muito entediada por ter de esperar as próximas férias para que possamos nos encontrar de novo...” no qual foram apagadas as marcas de proximidade, usada no primeiro exemplar da carta, tipicamente de uma conversação informal.

Se considerarmos a afirmação de Tannen (1982) de que, no gênero carta, a mensagem figura como elemento secundário, se comparada ao envolvimento entre os sujeitos, podemos afirmar que a atividade analisada contribui para que o aluno perceba que a carta, considerando a sua finalidade, depende, em parte, do reconhecimento das estratégias de proximidade, as quais dão ao leitor a impressão de estarem juntos um do outro. Nessa perspectiva, a C1 mostra para o aprendiz que, embora a relação entre a fala e a escrita apresente suas especificidades, a relação de proximidade ou distanciamento entre os interlocutores contribuem para as aproximações entre o texto oral e o texto escrito, quando analisados no contínuo. Sob esse ângulo, não há uma ruptura entre o texto oral e o texto escrito, mas uma aproximação entre as modalidades, condicionada por inúmeros fatores que interferem em toda a sua produção e realização.

No repertório de propostas trazidas por $\mathrm{C} 2$, encontramos um grande investimento de gêneros textuais cuja abordagem enfoca diferentes culturas populares, entre eles, alguns exercícios se propõem trabalhar a fala e a escrita através do gênero textual lenda. A atividade abaixo traz um recorte de como o ensino se realiza. Vejamos: 


\section{Exemplo 07:}

(C2/L3/U3:20) As histórias que você vai ler agora fazem parte do folclore africano e do folclore dos aborígines australianos. Conheça-as.

\section{(Fragmento 1) NAPI, OS HOMENS E OS ANIMAIS}

No início do mundo nasceu o Sol, e depois desse surgiu Napi, o criador, o guardião da vida. Um dia Napi descansava perto de uma fonte. Olhou para a terra úmida e teve uma idéia: pensou que seria divertido moldar pequenas criaturas de argila [...]

(História do folclore africano - Lá vem a história:

contos do folclore mundial, Editora Companhia das Letrinhas).

\section{(Fragmento 2) O TERRÍVEL HOMEM-GATO}

Kininie-Ger era um monstro com cabeça de gente e corpo de gato. Insensível, devorava crianças, animais ou o que quer que surgisse em seu caminho. Os homens da tribo Canguru revezavam-se montando guarda à noite para evitar que alguém fosse comido pelo monstro [...]

(História do folclore australiano - Lá vem a história:

contos do folclore mundial, Editora Companhia das Letrinhas).

Discuta com sua professora e colegas

- De acordo com essa história, quem criou os animais que vivem sobre a terra?

Por que, segundo a história, o homem continua até hoje, procurando novos lugares para morar?

- $\quad$ Se as lendas fazem parte do modo como um povo tenta entender e explicar fatos da vida, é possível afirmar que a história "Napi, os homens e os animais" seja uma lenda? Por quê?

(MP/ C2/L1/U/:32) Pode-se ampliar essa atividade, gravando a narração da lenda em fita cassete para que, depois, possa ser ouvida e comparada com a versão escrita. Espera-se que os alunos cheguem às seguintes conclusões quanto a aspecto da linguagem escrita e da linguagem oral das lendas:

a) a seleção do que se diz quando se escreve: evitam-se as dúvidas, as repetições e as hesitações;

b) a escrita deve primar pela clareza, pois não pode, como na oralidade, ser acompanhada de gestos, expressões faciais, entonações;

c) Há um esforço maior, na escrita, para ordenar as ideias e hierarquizá-las;

d) é preciso dedicar-se à preparação do que se vai escrever: roteiro prévio, construção de texto, revisão etc.

Podemos observar, através desta atividade, o enfoque que a C2 dá ao gênero lenda. A proposta inicial concentra-se na leitura das lendas e discussão do texto com os alunos e o professor. A tarefa visa estimular a interação cotidiana em sala de aula, sendo este evento orientado por questões cujo núcleo é o resgate das informações contidas no texto. Essa característica de exploração é percebida em todos os momentos em que o gênero lenda é abordado pela coleção.
No desenvolvimento da tarefa, o aluno é orientado a refletir sobre as características do gênero, através do seguinte questionamento (C2/L3/U3:20): Se as lendas fazem parte do modo como um povo tenta entender e explicar fatos da vida, é possível afirmar que a história "Napi, os homens e os animais" seja uma lenda? Por quê? Neste recorte, vemos a C2 apontando, de forma sucinta, características que definem o gênero lenda e conduzindo a reflexão sobre o texto. Dessa forma, 
oportuniza o aluno identificar, no texto trabalhado, os elementos que sinalizam a lenda como uma criação popular que represente a visão de um povo.

No MP encontramos sugestão de ampliação da atividade, em que é sugerida a audição de fitas, no intuito de trabalhar a comparação da lenda na versão oral e escrita (MP/C2/L1/U3:32): Pode-se ampliar essa atividade, gravando a narração da lenda em fita cassete para que, depois, possa ser ouvida e comparada com a versão escrita. Como sabemos, o uso da gravação e audição de fitas é um dos recursos que favorece a reflexão sobre o gênero textual presente nas duas modalidades de uso. Podendo ser ampliado para o trato com diferentes gêneros textuais, sistematizando uma reflexão sobre a língua (MARCUSCHI, 2001).

Através da comparação das versões oral e escrita da lenda, a C2 pontua alguns elementos que objetiva ver o aluno compreender. Entre eles, podemos destacar a ênfase na clareza da escrita em comparação à fala, atribuindo à primeira um maior cuidado na ordenação das ideias e um afrouxamento da segunda no ato de sua produção. Decorre disso alguns mitos estabelecidos socialmente, entre eles o de que a fala é dependente, não planejada, fragmentária, o lugar do “caos”, enquanto que a escrita se configura como autônoma, explícita, precisa (MARCUSCHI, 2001, 2008). Por este discurso, a C2 reforça o princípio de análise da fala - escrita tomando o oral espontâneo ou o falar diário, comparando-o a uma escrita formal, já tendo passado por um processo de releitura e revisão.

De acordo com Dolz e Schneuwly (2004, p. 158), focar-se sob o “aspecto caótico" da linguagem oral e tomar como referência o discurso organizado pela escrita é contemplar tão somente as "hesitações, titubeios, reformulações, retomadas ecóicas, balbucios, falsos inícios e falsas cadências, fáticos onipresentes, inicio de turnos abortados, quebras, interrupções, latidos, suspiros”. Observando esses elementos, nos concentramos no que por muitos autores é considerado como "a escória do oral espontâneo”. Conforme Marcushi (2001) é preciso compreender bem que oral e que escrita estamos buscando relacionar para que a análise não se apoie em uma supremacia ou superioridade de uma modalidade em relação à outra. Portanto, a análise deve ter clareza quanto ao aspecto que se está comparando e considerar que esta relação não é homogênea nem constante.

Decorre de encaminhamentos, como o dado pela tarefa acima, análises que tomam como referência elementos da fala e da escrita que pertencem a fenômenos discursivos “a priori” distintos, já que os processos e as condições de produção são diferenciados. Embora a C2 tenha trazido o gênero textual lenda, ainda que sob formas distintas de realizações (escrita/oralizada, oralizada/transcrita), o destaque é dado aos diferentes recursos utilizados por cada modalidade, esquecendo-se de que, no continuum, a lenda apresentada na modalidade escrita e na modalidade falada apresenta mais aproximações que diferenças no tocante ao grau de formalismo marcada no registro.

São orientações inadequadas, como os trazidos nessa questão, que favorecem uma identificação e avaliação da fala com base na escrita em um "quadro de dicotomias estritas porque predomina o paradigma teórico da análise imanente ao código” (MARCUSCHI, 2001). Os encaminhamentos dados pela atividade induzem a um olhar dicotômico e centram a reflexão fora do continuum, demonstrando uma inconsistência no trato com as modalidades de uso da língua e desprezando o fato de que as funções do gênero textual são igualmente importantes para a sociedade. 
A C1 também apresenta em sua proposta de ensino o trabalho com o gênero lenda. Trazemos para a análise o mesmo gênero abordado pela C2, para que possamos compreender qual o direcionamento da C1 no sentido de fazer o aluno compreender a relação fala - escrita:

\section{Exemplo 08:}

(C1/L2/U3:154) [...] lembrem-se daquilo que o Negrinho do Pastoril disse ao capataz, antes de ser levado para longe pelo bando de passarinhos.

- alguns de vocês vão representar o Negrinho e dizer o que ele disse - sem consultar o texto!

- agora, leiam no texto o que o negrinho disse e tentem analisar as diferenças entre o que foi falado pelos colegas e o que está escrito.

- concluam: nem sempre a gente escreve como fala, nem sempre a gente fala como escreve.

(MP/C1/L2/U3:154) será interessante que o professor registre no quadro - de- giz a fala de um dos alunos, para depois comparar mais facilmente o que foi falado com o que está escrito no texto. Discuta a conclusão com os alunos: há textos escritos de forma mais próxima como se fala, há situações em que as pessoas falam de forma próxima à escrita - dependendo o que se fala, onde, para quem, com que objetivo.

A tarefa acima é a culminância de uma sequência de atividades proposta pela C1 para desenvolver uma análise da relação fala - escrita. No encaminhamento do trabalho, o aluno é orientado a representar o texto "Negrinho do Pastoril” para que a sua fala seja registrada. Diferente da C2 que sugere a gravação e audição da fita, a C1 pede que o professor anote a fala do aluno e posteriormente compare ao texto escrito. As duas formas de registrar são significativas, à medida que se oportuniza a observação das estratégias orais e escritas no desenvolvimento do texto em suas modalidades de uso.

A indicação da C1 é que, após a representação, o aluno venha a analisar as diferenças entre o texto escrito e o texto oralizado (C1/L2/U3:154): “agora, leiam no texto o que o negrinho disse e tentem analisar as diferenças entre o que foi falado pelos colegas e o que está escrito” (grifo nosso). A proposta incide em uma reflexão que contempla a fala e a escrita, observadas em suas diferenças, porém, dentro do continuum. Visto que a discussão é norteada para a conclusão de que um texto oral ou escrito pode se aproximar, assim como se distanciar. Fato este compreendido quando se percebe a efetivação das modalidades de uso da língua através dos gêneros textuais, alocados em contínuos de produções especificas.

$\mathrm{Na}$ atividade acima, a C1 indica que o aluno poderá identificar, além de elementos que possam aparecer no texto oral, tais como as hesitações, as repetições, as pausas, os elementos prosódicos; observar, também, o que o texto escrito oferta para representar os elementos multissistêmicos típicos das realizações orais, ou seja, atentar-se para a questão da multimodalidade, visto que a encenação pede a associação de diferentes recursos em sua execução (DIONÍSIO, 2005).

Enfocando a condição de proximidade entre o texto escrito e o oral, (MP/C1/L2/ 
U3:154) "há textos escritos de forma mais próximas como se fala, há situações em que as pessoas falam de forma próxima à escrita - dependendo o que se fala, onde, para quem, com que objetivo", a C1 chama a atenção para os processos de enunciação que definem essa condição. Esses processos dão conta dos aspectos ligados ao conteúdo textual, à situação comunicativa, ao interlocutor e ao objetivo pretendido em determinada produção, resgatando o sentido das práticas sociais interativas entre os sujeitos.

Pudemos observar na análise das atividades ligadas à relação fala - escrita que as coleções buscam tratar o tema através de diferentes gêneros textuais. Ao compararmos as orientações dadas pela C1 e pela C2, podemos compreender que enquanto a primeira coleção parece analisar as produções orais e escritas em função das relações que ambas estabelecem nas práticas sociais, a segunda coleção dá indicações de que avalia o texto oral em função do que se espera do texto escrito, já tendo este passado por um processo de revisão, podendo ser tido como uma versão definitiva de um escrito. De acordo com Dolz e Schneuwly (2004, p. 158), essa é uma visão que carrega em si "um profundo viés ideológico”, pois sinaliza para uma concepção de língua que despreza as relações entre fala e escrita e centra-se nos elementos que as diferenciam.

\section{Para não concluir...}

Os encaminhamentos trazidos pelas coleções contemplam a demanda exigida pelos documentos oficiais, no sentido de ensinar os gêneros textuais que transcendem aos espaços privados de produção, ou seja, os gêneros textuais mais formais. A partir do que é proposto pelos LD, chega à escola um repertório de atividade embasada na discussão sobre os gêneros, demandando da prática docente a responsabilidade de sistematizar esse ensino, de modo a ampliar a competência comunicativa do aprendiz para o uso da fala pública formal, relativamente estabilizado na variedade textual.

Embora vejamos que as coleções por nós analisadas oportunizem ao discente um espaço consistente de reflexão sobre a linguagem oral, os gêneros propostos para o ensino-aprendizagem da fala em seu domínio público estão ligados ao espaço de produção estritamente escolar, ou seja, há uma ênfase na escolarização do gênero, o que demanda da escolar um esforço de refletir também sobre os gêneros textuais em seu ambiente real de produção e realização.

Algumas inquietações, fruto de nossa pesquisa, foram respondidas, dentre elas, aquela que diz respeito ao trato das relações fala - escrita. Vimos que as coleções apresentam traços diferenciados de encaminhamentos para a análise do objeto de estudo. Enquanto a C1 considera a relação fala - escrita na dimensão do contínuo tipológico dos gêneros textuais, respondendo a uma noção de língua sociointerativa, a C2 direciona uma reflexão da língua falada do ponto de vista do que se espera de uma escrita 'padrão', que pode representar para a C2, que a normatividade parece ser um dos objetivos centrais ao tratar da oralidade.

A C2 toma as polarizações como centro das abordagens, sustentando uma visão de língua cujo foco é o ‘código’, contradizendo as bases dialógicas. Perspectiva que parece nortear os documentos oficiais que referência para o ensino da língua portuguesa. As atividades analisadas da referida coleção deixam lacunas ao observar a língua falada e escrita operando através de gêneros textuais, desprezando as relações de aproximação que 
ocorrem entre os gêneros, realizados na modalidade oral e na modalidade escrita.

Os resultados dessa investigação evidenciam a necessidade de se investigar com maior densidade as questões da relação fala - escrita, no sentido de promover debates e investigações sistemáticas sobre a didatização do referido eixo de análise. As evidências demandam um debruçar constante sobre a teoria e um olhar reflexivo sobre a prática, em busca de compreender com maior clareza o objeto de saber a ser tratado em nossos espaços escolares, bem como as concepções que norteiam os manuais didáticos, que guiam as práticas docentes.

O cenário pode nos encaminhar para algumas conclusões, dentre elas a de que as imprecisões na caracterização do fenômeno fala - escrita pode favorecer a incipiência no trato do conteúdo, cuja discussão caminha em busca de se estabelecer nos currículos das práticas escolares. Um encaminhamento comprometido com o fortalecimento das discussões que relacionam a fala e a escrita não deve tomar as modalidades com posição marcadamente contrárias, mas abordá-las sob o prisma das relações travadas a partir dos gêneros textuais. Dessa forma, fortalecemos bases sintonizadas com as demandas mais atuais para o ensino da língua materna.

\section{Referências}

BAKHTIN, M. Os gêneros do discurso. In: BAKHTIN, M. Estética da criação verbal. São Paulo: Martins Fontes, 1997.

Língua, fala e enunciação. In: BAKHTIN, M. Estética da criação verbal. São Paulo: Martins Fontes, 1992.
BATISTA, A. Recomendações para uma política pública de livros didáticos. Brasília: MEC/SEF, 2001.

BORTONI-RICARDO, S. Educação em língua materna: a sociolinguística em sala de aula. São Paulo: Parábola Editorial, 2004.

BRASIL. Guia do livro didático: 1a a 4a séries (PNLD 2004). Brasília: MEC/SEF, 2004.

. Parâmetros Curriculares Nacionais: Língua Portuguesa (1a a 4a série). Brasil; MEC-SEF, 1996.

CAVALCANTE, M. C. B; MELO, C. T. V. de. Oralidade no ensino médio: em busca de uma prática In: BUZEN, C.; MENDONÇA, M. (Orgs.). Português no ensino médio e a formação do professor. São Paulo: Parábola Editorial, 2006. p. 181-198.

COSTA-MACIEL, D. A. G. da. Oralidade e ensino: saberes necessários à prática docente. Recife: EDUPE, 2013.

DOLZ, J. e SCHNEUWLY, B. Gêneros orais e escritos na escola. Campinas: Mercado de letras, 2004.

. Gêneros e progressão em expressão oral e escrita: elementos para reflexões sobre uma experiência suíça (francófona). Enjeux, 1996: 31-49. Tradução provisória de Roxane Rojo, 1996.

DOLZ, J.; SCHNEUWLY, B. e HALLER, S. O oral como texto: como construir um objeto de ensino. In: SCHNEUWLY B.; DOLZ, J. Gêneros orais e escritos na escola. Campinas: Mercado de Letras, 2004. p. 149185.

DOLZ, J.; SCHNEUWLY, B; PIETRO, J.F. de e ZAHND, G. A exposição oral. In: ROJO, R. e CORDEIRO, G. de S. (orgs.). Gêneros orais e escritos na escola. Campinas: Mercado de Letras, 2004. p. 215-246. 
FÁVERO, L. L. Oralidade e escrita: perspectiva para o ensino da língua materna. São Paulo: Cortez, 2000.

FÁVERO, L. L.; ANDRADE, M. L.; AQUINO, Z. A. Reflexões sobre oralidade e escrita no ensino de língua portuguesa. In: ELIAS, V. M. (Org.). Ensino de língua portuguesa: oralidade, escrita, leitura. São Paulo: Editora Contexto, 2011. p.13-27.

GERALDI, J. W. Portos de passagem. São Paulo: Martins fontes, 1997.

GOMES, S. Coleção vitória-régia. Campina Grande do Sul: Lago, 2000.

GUMPERZ, J. J. Discourse strategies. London: Cambridge University Press, 1982.

KLEIMAN, A. B. Texto e leitor: aspectos cognitivos da leitura. Campinas: Pontes, 1995.

KOCH, I. V. O texto e a construção dos sentidos. São Paulo: Contexto, 2002.

LAJOLO, M. Livro didático e qualidade de ensino. In: Em Aberto. Ministério da Educação e Desporto SEDIAE/ INEP. Ano 16: $n^{\circ} 69,1996$.

MAGALHÃES, T. G. Concepção de oralidade: a teoria nos PCN e no PNLD e a prática nos livros didáticos. 2007. 211 p. Tese (Doutorado) Universidade Federal Fluminense. Rio de Janeiro.

MARCUSCHI, L. A. Produção textual, análise de gêneros e compreensão. São Paulo: Parábola editorial, 2008.

Oralidade e ensino de língua. In: DIONÍSIO, A. P. O livro didático de português: múltiplos olhares. Rio de Janeiro: Lucerna, 2005.

. Gêneros textuais: o que são e como se constituem. Recife: UFPE, 2002.
. Da fala para a escrita: atividades de retextualização. São Paulo: Cortez 2001. - Análise da conversação. São Paulo: Editora Ática, 1999.

- Oralidade e escrita. II Encontro Franco Brasileiro De Ensino De Língua. Anais... Natal, 1995.

MARCUSCHI, L.A.; DIONISIO, A. (Orgs.). Fala e escrita. Belo Horizonte: Autêntica, 2005.

MARTINS, M. S. C.. Letramento, interdisciplinaridade e multiculturalismo no ensino fundamental de nove anos. Campinas: Mercado de Letras, 2012.

MEDINA, C. de A. Entrevista: o diálogo possível. São Paulo: Editora Ática, 1986.

MENDES, A. N. N. B. A linguagem oral nos livros didáticos de língua portuguesa do ensino fundamental - $3^{\circ}$ e $4^{\circ}$ ciclos: Algumas Reflexões. 2005. 211 p. Tese (Doutorado) Programa de Pós-Graduação em Linguística, Pontifícia Universidade Católica de São Paulo, São Paulo.

MENDES DA SILVA, P.; MORI-DEANGELIS, C. Livros didáticos de língua portuguesa ( $5^{\mathrm{a}}$ a $8^{\mathrm{a}}$ séries): perspectivas sobre o ensino da linguagem oral. In: ROJO, R. BATISTA, A. A (Orgs.). Livro didático de língua portuguesa, letramento e cultura escrita. São Paulo: Mercado das letras, 2003.

MINAYO, M. C. S. (Org.). Ciência, tecnologia e arte: o desafio da pesquisa social. Petrópolis: Vozes, 1994.

MORAIS, A. G.; ALBUQUERQUE, E. B. C. (Orgs.). Alfabetização: apropriação do sistema de escrita alfabético. Belo Horizonte: Autêntica, 2005.

RANGEL, E. Livro didático de língua portuguesa: o retorno do recalcado. In: DIONÍSIO, A.; BEZERRA, M. A. O livro 
didático de português: múltiplos olhares. Rio de Janeiro: Lucerna, 2001.

RUBIO, M.; ARIAS, V. Uma secuencia didáctica para la ensenanza de la argumentación escrita em el tercer ciclo. Lectura y vida, La Plata, n. 4, p. 34-43, 2002.

SCHNEUWLY, B. Gêneros e tipos de discurso: considerações psicológicas e ontológicas. In: SCHNEUWLY, B.; DOLZ, J. Gêneros orais e escritos na escola. Campinas: Mercado de letras, 2004.

SCHNEUWLY, B.; DOLZ, J. O oral como texto: como construir um objeto de ensino. In: SCHNEUWLY, B.; DOLZ, J. Gêneros orais e escritos na escola. Campinas: Mercado de letras, 2004.

SILVA, E. T. Livro Didático: do ritual de passagem à ultrapassagem. In: Em Aberto. Ministério da Educação e Desporto SEDIAE/ INEP. Ano 16. nº 69, 1996.

SILVA, F. F.; LEAL, T. F. O livro didático: interface com outros portadores de textos In: LEAL, T.; SILVA, A. (Orgs.). Recursos didáticos e ensino de lingual portuguesa: computadores, livros e muitos mais. Curitiba: Editora CRV, 2011.

SOARES, M. Português: uma proposta para o letramento. São Paulo: Editora Moderna, 1999.

TANNEN, D. The oral/literate continuum in discourse. In: TANNEN, D. Spoken and written language: exploring orality and literacy. Norwood, NJ: Ablex, 1982.

TRAVAGLIA. L. C. Gramática e interação: uma proposta para o ensino de gramática no $1^{\circ}$ e $2^{\circ}$ graus. 3. ed. São Paulo: Cortez, 1995. 